\title{
ПРИМЕНЕНИЕ КОРРЕКЦИОННО-РАЗВИВАЮЩИХ ТЕХНОЛОГИЙ В ПРОЦЕССЕ РАЗВИТИЯ ПСИХОМОТОРНЫХ ФУНКЦИЙ У ДОШКОЛЬНИКОВ С ОГРАНИЧЕННЫМИ ВОЗМОЖНОСТЯМИ ЗДОРОВЬЯ 1
}

\section{THE APPLICATION OF CORRECTION- \\ DEVELOPING TECHNOLOGIES IN \\ THE PROCESS OF DEVELOPMENT \\ OF PSYCHOMOTOR FUNCTIONS IN PRESCHOOLERS WITH DISABLED HEALTH \\ S. Arkhipova M. Podshivalova}

Summary: This article analyzes the results of a study on the use of correctional and developmental technologies, in particular kinesitherapy technology, in the development of psychomotor functions in preschool children with disabilities.

Keywords: correctional and developmental technologies, kinesitherapy, psychomotor functions, development, limited health opportunities, preschool children with disabilities.

\section{Введение}

$\mathrm{H}$ а современном этапе развития общей и специальной дошкольной педагогики и психологии актуальным направлением является совершенствование имеющихся и проектирование новых коррекционно-развивающих технологий, направленных на развитие психомоторных функций у детей дошкольного возраста с ограниченными возможностями здоровья (далее ОВ3). Это обусловлено тем, что развитие и дальнейшее формирование психики и моторики неразрывно взаимосвязаны с самого рождения ребенка.

Изучение проблемы развития психомоторных функций у дошкольников с ОВ3 является на сегодняшний день значимым, поскольку, с одной стороны их количество с каждым годом неуклонно растет, а с другой - полноценное развитие психомоторных функций является базисом для дальнейшего обучения в школе. От уровня развития психомоторных функций зависит успешность

\author{
Архипова Светлана Владимировна \\ К.п.н., дочент, ФГБОУ ВО «Мордовский государственный \\ педагогический университет \\ имени М.Е. Евсевьева» (2. Саранск) \\ arhipova.swetlana2011@yandex.ru \\ Подшивалова Маргарита Сергеевна \\ ФГБОУ ВО «Мордовский государственный педагогический \\ университет имени М.Е. Евсевьева» (2. Саранск) \\ rita.podshivalova@yandex.ru
}

Аннотация: В материалах данной статьи анализируются результаты проведенного исследования по применению коррекционно-развивающих технологий, в частности технологии кинезитерапии, в процессе развития психомоторных функций у детей дошкольного возраста с ограниченными возможностями здоровья.

Ключевые слова: коррекционно-развивающие технологии, кинезитерапия, психомоторные функции, развитие, ограниченные возможности здоровья, дошкольники с ограниченными возможностями здоровья. овладения рисованием, чтением, письмом и другими видами учебной деятельности.

В моторной неловкости, некоординированных движениях, низкой двигательной переключаемости, искажении пространственно-временных представлений, быстрой утомляемости, неустойчивой эмоциональноволевой регуляция деятельности и др. кроются причины возникновения различных трудностей в ходе дошкольного, а затем и школьного образования детей с ОВЗ. Это обстоятельство обуславливает необходимость выстраивать коррекционно-педагогический процесс таким образом, чтобы он оказывал положительное влияние на развитие психомоторных функций как интегративную составляющую системы всего онтогенетического цикла дошкольника. Возникает потребность в поиске новых коррекционно-развивающих технологий развития психомоторных функций у детей с ОВ3, одной из которых является технология кинезитерапии. Значимость технологии кинезитерапии заключается в ее универсально-

Исследование выполнено при финансовой поддержке вуза-партнера ФГБОУ ВО «Чувашский государственный педагогический университет им. И.Я. Яковлева» по теме: «Применение коррекционно-развивающих технологий в процессе развития психомоторных функций у дошкольников с ограниченными возможностями здоровья» (№ 35/2020, дата рег:: 16.04.2020). 
сти. Кинезитерапевтические упражнения способствуют развитию всех компонентов психомоторных функций.

Продуктивная реализация данной деятельности невозможна без качественного организационно-методического обеспечения. Однако, в специальной литературе крайне мало научно-методических рекомендаций, посвященных проблеме использования кинезитерапевтических упражнений для развития психомоторики дошкольников с ОВЗ.

Актуальность обозначенной проблемы определила цель работы, заключающуюся в применении коррекционно-развивающих технологий, в частности технологии кинезитерапии, в процессе развития психомоторных функций у детей дошкольного возраста с ОВ3.

Понятие «психомоторные функции» не имеет однозначного устоявшегося определения: это и конечное звено психической деятельности, обусловленное тесной связью психических процессов с движением (И.М. Сеченов) [12]; и вариативность психически обусловленных движений человека, типологически различных, зависящих от пола, возраста, строения тела и т. п. (В.В. Никандров) [10]; и совокупность осознанно выполняемых двигательных манипуляций, процесс, объединяющий психику и ее двигательное выражение (М.В. Александров, М.С. Березанцева, С.А. Лытаев) [9]; и вид объективизации психики в сенсомоторных, идеомоторных и эмоционально-моторных (в частности, импульсивных) реакциях и актах (К.К. Платонов) [11]; и комплекс психических (сенсорных, интеллектуальных, речевых, эмоциональных) и моторных качеств (М.О. Гуревич, Н.И. Озерецкий) [3] и др.

Представленные выше определения данного понятия позволяют обобщить его основные характеристики и заключить, что психомоторные функции представляют связь двигательных действий с психическими процессами (познавательными, речевыми, эмоционально-волевыми).

Обозначенное понимание психомоторных функций дает возможность выделить следующие основные составляющие для их изучения: двигательный, познавательный и эмоционально-волевой компоненты, на которых и акцентируется внимание в рамках проведенного исследования с дошкольниками, имеющими ОВ3 [2].

Следует отметить, что контингент дошкольников с ОВЗ крайне неоднороден. К ним относят детей, развитие психических функций которых отклоняется от нормы из-за врожденного дефекта или приобретенного органического поражения сенсорных органов, опорно-двигательного аппарата или центральной нервной системы. Это не только дети с умственной отсталостью, недостат- ки интеллекта которых значительно выражены, и являются следствием тяжелых повреждений центральной нервной системы. Но, и дети, чьи проблемы развития обусловлены дефектом формирования интеллектуальной деятельности вследствие негрубых органических или функционально-динамических нарушений центральной нервной системы [14]. Психомоторное развитие дошкольников с ОВЗ значительно отличается от нормально развивающихся сверстников в двигательном, познавательном и эмоционально-волевом аспектах [4].

В.П. Дудьев, Л.Т. Журба, А.В. Запорожец, А. Зарин, М.М. Кольцова, Е.М. Мастюкова и др. отмечают, что развитие психомоторных функций дошкольников с ОВ3 протекает неравномерно, и может довольно широко отличаться по темпу, но при этом сохранять четкую последовательность в становлении двигательного, познавательного и эмоционального компонентов [4; 5; 9].

Тенденции развития психомоторных функций близких к норме отмечаются только при легких, неосложненных нарушениях. При тяжелых, множественных, осложненных нарушениях - общие черты онтогенеза исчезают.

В работах Л.В. Лопатиной, А.С. Стрекалова, Е.С. Черновой отмечается, что для двигательной сферы дошкольников с ОВЗ характерна несформированность зрительно-двигательных координаций, недоразвитие общей, мелкой, мимической и артикуляционной моторики. С возрастом моторная недостаточность сглаживается, но чем грубее недоразвитие центральной нервной системы, тем слабее влияет возрастной фактор на состояние психомоторных функций. У всех детей данной категории развитие речи отличается качественным своеобразием, бедность и стереотипность речевых реакций препятствует полноценному использованию вербальных средств для закрепления сложных двигательных актов $[8 ; 14]$.

По мнению Х.М. Евлоевой, А.Д. Ложечкиной, на развитии познавательной сферы детей с ОВ3 негативно сказываются низкая познавательная активность, несформированность пространственных представлений, отсутствие образности мыслительных операций, интуитивный характер мышления, слабая переключаемость внимания и быстрая утомляемость [7].

С точки зрения В.П. Дудьева, А. Зарин, Я.Л. Коломинского, Ю.В. Нефедовой эмоционально-волевая сфера детей дошкольного возраста с ОВ3, характеризуется несфомированностью процессов саморегуляции и самоконтроля, которые важны для развития произвольного поведения и организации собственной деятельности. Детям трудно соотносить предъявляемые правила и требования с собственными действиями, они пасуют при возникновении каких-либо трудностей. Отклонения 
эмоциональной сферы такие, как эгоцентричность, нерешительность, упрямство, негативизм и т. д. провоцируют проблемы в организации социальных коммуникаций, а трудности общения подпитывают эмоциональное напряжение и чувство тревоги $[4 ; 5 ; 6]$.

Перечисленные особенности психомоторных функций дошкольников с ОВЗ актуализируют применение для их развития коррекционно-развивающих технологий, одной из которых является кинезитерапия.

В материалах данной статьи мы обсуждаем результаты проведенного нами исследования по применению коррекционно-развивающих технологий в процессе развития психомоторных функций у детей дошкольного возраста с ОВ3.

Экспериментальное исследование было организовано на базе МДОУ «Детский сад № 65 комбинированного вида» и МДОУ «Детский сад № 78 комбинированного вида» г. Саранск (Россия). В исследовании приняли участие 20 воспитанников старших групп компенсирующей направленности в возрасте 5-6 лет, имеющих заключение ПМПК «Локальное поврежденное развитие. Общее недоразвитие речи I уровня», «Диффузное поврежденное развитие. Общее недоразвитие речи І уровня», «Парциальная недостаточность когнитивного компонента деятельности. Общее недоразвитие речи II уровня», «Парциальная недостаточность вербального компонента деятельности. Общее недоразвитие речи III уровня».

Экспериментальная работа была организована в три этапа. На первом этапе проводилась диагностика уровня развития психомоторных функций дошкольников с OB3, на втором - их развитие посредством кинезитерапии, на третье этапе - выявление эффективности экспериментальной работы.

В ходе исследования психомоторных функций у дошкольников с ОВЗ были обнаружены: отклонения от нормы развития в динамической и статической координации; трудности организации движений в пространстве; неточности при выполнении поз пальцев обеих рук; нарушение темпа выполнения движений; несформированность уклада мышц артикуляционного отдела периферического речевого аппарата. Дети испытывают сложности при выполнении и удержании мимических поз, переключении движений губ, щек, языка. Важно отметить, что дошкольникам данной категории очень сложно выполнять задания по словесной инструкции, они нуждаются в повторном и подробном разъяснении или демонстрации упражнения. Учитывая результаты исследования, мы разделили испытуемых на две дифференцированные группы.

Группа «А» $(40$ \%) - дошкольники с низким уровнем развития психомоторных функций - характеризовалась отсутствием скоординированности движений рук, ног, пальцев и языка; вялыми, скованными, неточными движениями; низким уровнем развития зрительной ориентировки, целостного восприятия, наглядно-образного мышления; выполнением заданий по образцу или по показу; неустойчивым вниманием, слабой памятью и отсутствием самоконтроля.

Группа «Б» (60 \%) - дошкольники со средним уровнем развития психомоторных функций - характеризовалась быстрой истощаемостью силы движений, слабой координацией мышц ног, рук, пальцев и языка; недостаточным уровнем развития целостного восприятия, наглядно-образного мышления и зрительной ориентировки; неустойчивым вниманием и слабым самоконтролем.

Данные диагностики подтвердили наше предположение о необходимости совершенствования традиционной методики развития психомоторных функций у дошкольников с ОВЗ. Одним из путей решения данной проблемы нам видится применение коррекционно-развивающих технологий, в частности, технологии кинезитерапии.

Кинезитерапия (кинезиотерапия, кинезотерапия) представляет реабилитационную методику, вариант лечебной физической культуры. Теоретической основой кинезитерапии является кинезиология - наука о совершенствовании умственных способностей и физического развития через определенные движения, направленные на гармоничное межполушарное взаимодействие [12].

В коррекционной работе, направленной на развитие психомоторных функций у детей с ОВ3, кинезитерапию применяют с целью совершенствования способности левого и правого полушария головного мозга к интеграции, позволяющей активизировать высшие психические функции.

Значимость технологии кинезитерапии заключается в ее универсальности. Кинезитерапевтические упражнения способствуют развитию двигательного компонента психомоторных функций. Благодаря комплексам упражнений, направленных на развитие крупной моторики, совершенствуется координация движений, ориентация в пространстве и собственном теле, появляется уверенность при ходьбе, прыжках и беге. Развивается способность немедленного реагирования и ловкость в игре с мячом. Упражнения, нацеленные непосредственно на формирование тонкой моторики, способствуют овладению способностью умело пользоваться ножницами, свободно рисовать карандашом и красками.

Систематическое применение кинезитерапевтических телесных, глазодвигательных и дыхательных упраж- 
нений, помимо прямого предназначения, способствует формированию межполушарного взаимодействия, оказывающего стимулирующее влияние на работоспособность головного мозга и развитие познавательного компонента психомоторных функций. Использование технологии кинезитерапии оказывает как мгновенный, так и накапливающий эффект повышения уровня интеллектуальных возможностей и умственной работоспособности.

Данная технология оказывает благоприятное воздействие и на развитие эмоционально-волевого компонента, т. е позволяет минимизировать чувство тревоги и эмоциональное напряжение, нормализовать процессы саморегуляции и самоконтроля, которые влияют на организацию собственной деятельности и поведения, что способствует успешной социальной коммуникации.

Разрабатывая содержание экспериментальной работы, мы также учитывали тот факт, что наиболее эффективными и проверенными способами и средствами обучения и воспитания детей дошкольного возраста являются сказки [1].

Сказкотерапия в коррекционно-развивающей работе играет ведущую роль. Сказки помогают ребенку адаптироваться к жизни, развивают фантазию и образное мышление, избавляют от стереотипного мышления, совершенствуют средства выразительности - пластику, мимику и речь.

В связи с этим, мы считаем целесообразным для развития психомоторных функций у дошкольников с ОВ3 слияние двух психотерапевтических технологий: сказкотерапии и кинезитерапии. Включение сказок в элементы кинезитерапии позволяет замотивировать детей на выполнение упражнений, активизировать их мыслительную и речевую деятельность.

Технология работы заключалась в подборе и адаптации кинезитерапевтических упражнений, ориентированных на каждого ребёнка в соответствии с исходным уровнем развития психомоторных функций, и соединении их со сказкой. Активное участие самого ребёнка в коррекционно-развивающем процессе в качестве субъекта формировало у него положительный эмоциональный настрой и мотивацию, что способствовало повышению эффективности развития психомоторных функций.

Занятия организовывались в подгрупповой форме два раза в неделю по 20-30 минут, в зависимости от психоэмоционального настроя обучающихся.

Работа с кинезитерапевтическими сказками была организована поэтапно. Первый этап - игра-приветствие: «Приветствие Говоруши» (развитие навыка вступать в контакт и настраиваться на дальнейшую работу в позитивном ключе); «Передай улыбку» (обучение элементам мимики, выразительных и четких движений); «Комплимент» (способствовать повышению уверенности в себе); «Я рад тебя видеть!» (обучение способности передавать чувство радости, используя вариативные эмоциональные средства). Второй этап включал рассказ с демонстрацией сказки педагогом. Затем проводилась беседа по сказке, разбор ее сюжета и персонажей. На четвертом этапе непосредственно отрабатывалась техника кинезитерапевтических упражнений по сказке. При разучивании упражнений, все движения выполнялись сначала правой рукой, затем левой, и только потом синхронно обеими руками. Упражнения, включающие связку из нескольких движений, отрабатывались полностью; при демонстрации же могли использоваться отдельные элементы связки. Комплекс упражнений включал: растяжки, направленные на нормализацию гипертонуса и гипотонуса; дыхательные упражнения, способствующие улучшению ритмики и осанки, развитию самоконтроля и произвольности; глазодвигательные упражнения, нацеленные на расширение поля зрения и улучшение восприятия; телесные движения, оказывающие воздействие на устранение непреднамеренных движений и зажимов.

Роль педагога заключалась в непосредственном обучении дошкольников данным упражнениям, их демонстрации с пояснениями, а также непрерывном контроле всех движений. В зависимости от сложности, каждое движение выполнялось от 3-х до 5-и повторов (отдельные движения - 5 раз, связка движений, включающая два и более элемента - 3 раза). Заключительный этап включал релаксационные упражнения: «Винт» (расслабление корпуса тела и рук); «Кулачки» (снятие напряжения с пальцев рук»; «Любопытная Варвара» (расслабление мышц шеи); «Замедленное движение» (обучение позе покоя, расслабление всего тела), «Волшебный сон» с музыкальным сопровождением (расслабление, снятие эмоционального напряжения), которые способствовали мышечному расслаблению и снятию напряжения.

Приведём примеры кинезитерапевтических упражнений, которые были использованы в работе с дошкольниками с ОВ3.

Упражнение «Кошка»: попеременно менять положение руки «кулак» - «ладонь» сначала правой, затем левой, и обеими руками одновременно, произнося слова: «Кулачок-ладошка, так гуляет кошка».

Упражнение «Бутон»: руки направлять вверх, соприкасаясь основаниями ладоней, формируя чашу - «бутон закрыт». Ладони и пальцы развести в сторону - «бутон раскрылся».

Упражнение «Бабочка»: перекрестить ладони перед 
собой, изобразить «крылья бабочки».

Упражнение «Ухо-нос»: взяться левой рукой за правое ухо, а правой рукой за нос. Одновременно отпустив руки, хлопнуть в ладоши. Повторять данное упражнение, меняя положение рук и ускоряя темп.

Упражнение «Задуй свечу»: представить, что перед вами свечи - одна большая и пять маленьких. Сделав глубокий вдох, выполнить сильный выдох - задуть большую свечу. Затем, сделав глубокий вдох, совершить дозированно выдох маленькими порциями - задуть маленькие свечи.

Для максимально эффективного применения технологии кинезитерапии в развитии психомоторных функций у дошкольников с ОВЗ нами был разработан ряд методических рекомендаций для учителей-логопедов и воспитателей:

- технологию кинезитерапии рекомендуется применять ежедневно и систематично в рамках непосредственной образовательной деятельности и (или) в режимных моментах;

- форма организации может быть индивидуальной, подгрупповой и групповой;

- при выполнении упражнений важно сохранять спокойную, доброжелательную обстановку;

- в зависимости от содержания и направленности упражнения могут проводиться в различных положениях (сидя, стоя, лежа);

- выполнение новых упражнений проводится в медленном темпе (от 3 до 5 раз), начиная сначала с правой руки, затем левой и в завершении синхронно обеими руками;

- все указания и инструкции детям необходимо давать четко, внятно и спокойно;

- педагог выполняет упражнения вместе с детьми, постепенно увеличивая время и сложность предлагаемых упражнений (с учетом возраста и индивидуальных особенностей дошкольников);

- педагогу следует контролировать правильность техники выполнения упражнений детьми.

С целью выявления эффективности проведенной опытно-экспериментальной работы было проведено контрольное исследование уровня развития психомоторных функций у дошкольников с ОВ3.
По результатам диагностики мы разделили всех испытуемых на три дифференцированные группы: группа «A» $(20 \%)$ и группа «Б» (20 \%) - дети, продемонстрировавшие низкий и средний уровни развития психомоторных функций соответственно; группа «С» (60 \%) - дошкольники, продемонстрировавшие высокий уровень развития психомоторных функций. У детей данной группы были диагностированы свободные, уверенные, точно скоординированные движения ног, рук, пальцев и языка; высокий уровень развития зрительной ориентировки, познавательных процессов; самостоятельность и самоконтроль при выполнении заданий.

Исходя из данных констатирующего и контрольного экспериментов, можно проследить положительную динамику развития психомоторных функций у дошкольников с ОВ3. Данный анализ показывает, что количество детей с низким уровнем снизилось в два раза, показатели среднего уровня уменьшились в три раза, а высокий уровень развития психомоторных функций, отсутствующий до экспериментального обучения, был диагностирован более чем у половины испытуемых.

\section{Выво $\Delta ы$}

Необходимо отметить, что вопросы психомоторного развития дошкольников с ОВЗ средствами коррекционно-развивающих технологий, в частности технологии кинезитерапии, являются достаточно актуальным и перспективным направлением современных исследований. Однако дети с ОВ3 зачастую оказываются вне поля кинезитерапевтического воздействия из-за специфических особенностей своего дефекта. В результате опытно-экспериментальной работы нами была подтверждена предполагаемая гипотеза, что на процесс развития психомоторных функций у дошкольников с ОВЗ отрицательно влияют не только особенности их психофизического развития, но и недостатки традиционного обучения. В связи с этим, нам представляется возможным включить в работу по развитию психомоторных функций элементы технологии кинезитерапии. Ее применение позволяет формировать у дошкольников с ОВЗ пространственное восприятие и базовые сенсомоторные взаимодействия, обогащать чувственной информацией, переносить сенсорный опыт в самостоятельную деятельность, совершенствовать мелкую и крупную моторику, развивать самоконтроль, снимать психоэмоциональное напряжение.

ЛИТЕРАТУРА

1. Arkhipova, S.V. The formation of the coherent speech of junior schoolchildren with intellectual disabilities by means of animation-based therapy / S.V. Arkhipova, 0.S. Grishina, N.G. Minaeva, T.A. Mikheikina, N.V. Ryabova // Revista inclusiones. - 2019. - V. 6. Numero Especial - Octubre - Diciembre. - P. 47-62. - URL : http://www.archivosrevistainclusiones.com/gallery/5\%20vol\%206\%20num\%204\%20pernambucomund02019octubdiciemb19incl.pdf

2. Архипова С.В. Формирование психомоторных навыков у дошкольников с умственной отсталостью средствами коррекционной ритмики / С.В. Архипова, 
Т.В. Космачева. - Текст: непосредственный // Проблемы современного педагогического образования. Сер.: Педагогика и психология: Сборник научных трудов. - Ялта: РИО ГПА, 2018. - Вып. 59. - Ч. 3. - С. 33-36.

3. Гуревич М.О. Психомоторика / М.О. Гуревич, Н.И. Озерецкий. - М.: Гос. мед. изд., 1930. - 72 с.

4. Дудьев В.П. Психомоторика детей с ограниченными возможностями здоровья: учебное пособие / В.П. Дудьев; Алтайский государственный педагогический университет. - Барнаул: АлтГПУ, 2020. - 360 c. - URL: https://icdlib.nspu.ru/views/icdlib/8120/read.php (дата обращения: 27.09.2020). - ISBN 978-5-88210-960-7.

5. Зарин А. Динамика эмоционально-волевой сферы и поведения дошкольников с интеллектуальной недостаточностью / А. Зарин, Ю.В. Нефедова // Праздники и повседневность в жизни особого ребенка : материалы XXIV Международной конференции «Ребенок в современном мире. Детство: Праздник и повседневность»; под. ред. К.В. Султанов. - Санкт-Петербург: Изд-во РГПУ им. А.И. Герцена, 2017. - С. 80-82.

6. Коломенский Я.Л. Психическое развитие детей в норме и патологии / Я.Л. Коломенский, Е.А. Панько, С.А. Игумнов. - Санкт-Петербург: Питер, 2004. 480 c.

7. Ложечкина А.Д. Выявление особенностей познавательных процессов / А.Д. Ложечкина, Х.М. Евлоева // Психологическое здоровье личности: теория и практика. Сборник материалов IV Всероссийской научно-практической интернет-конференции; под. ред. И.В. Белашева. - Ставрополь: СКФУ. - 2017. C. 167-172.

8. Лопатина Л.В. Изучение и коррекция нарушений психомоторики у детей с минимальными дизартрическими расстройствами / Л.В. Лопатина // Дефектология, 2003. - № 5. - C. 45-51. - URL: https://www.elibrary.ru/item.asp?id=23367797 (дата обращения: 06.09.2020).

9. Лытаев С.А. Психофизиология: учебное пособие / С.А. Лытаев, М.С. Березанцева, М.В. Александров; под ред. Е.Г. Закревской. - Москва: СпецЛит, 2018. 256 c.

10. Никандров В.В. Психомоторика : учебное пособие / В.В. Никандров. - Санкт-Петербург: Речь, 2004. - 104 с. - URL : http://lib.mgppu.ru/0pacUnicode/app/ webroot/index.php?url=/notices/index/IdNotice:238469/Source:default (дата обращения: 03.04.2020). - ISBN 5-9268-0141-9.

11. Платонов К.К. Структура и развитие личности: психология личности / К.К. Платонов; под ред. А.Д. Глоточкина. - М. : Наука, 1986. - 256 с.

12. Сеченов И.М. Физиология нервной системы / И.М. Сеченов; под общ. ред. К.М. Быкова. - М. : Юрайт, 2019. - 330 с.

13. Сиротюк А.Л. Обучение детей с учетом психофизиологии / А.Л. Сиротюк - Москва: Сфера - 2002. - 128 c. - URL : https://www.studmed.ru/view/sirotyuk-alobuchenie-detey-s-uchetom-psihofiziologii_4eb58c6df7a.html (дата обращения 24.07.2020). - ISBN 5-89144-214-0.

14. Стрекалов А.С. Дифференциация детей старшего дошкольного возраста с интеллектуальными нарушениями на однородные группы по уровню развития двигательных и познавательных способностей / А.С. Стрекалов, Е.С. Чернова // Гаудеамус. - 2013. - № 1. - C. 129-134. URL : https://cyberleninka.ru/ article/n/differentsiatsiya-detey-starshego-doshkolnogo-vozrasta-s-umstvennoy-otstalostyu-na-odnorodnye-gruppy-po-urovnyu-razvitiya-dvigatelnyh-і (дата обращения: 06.10.2020).

○ Архипова Светлана Владимировна (arhipova.swetlana2011@yandex.ru), Подшивалова Маргарита Cepгеeвна (rita.podshivalova@yandex.ru). Журнал «Современная наука: актуальные проблемы теории и практики»

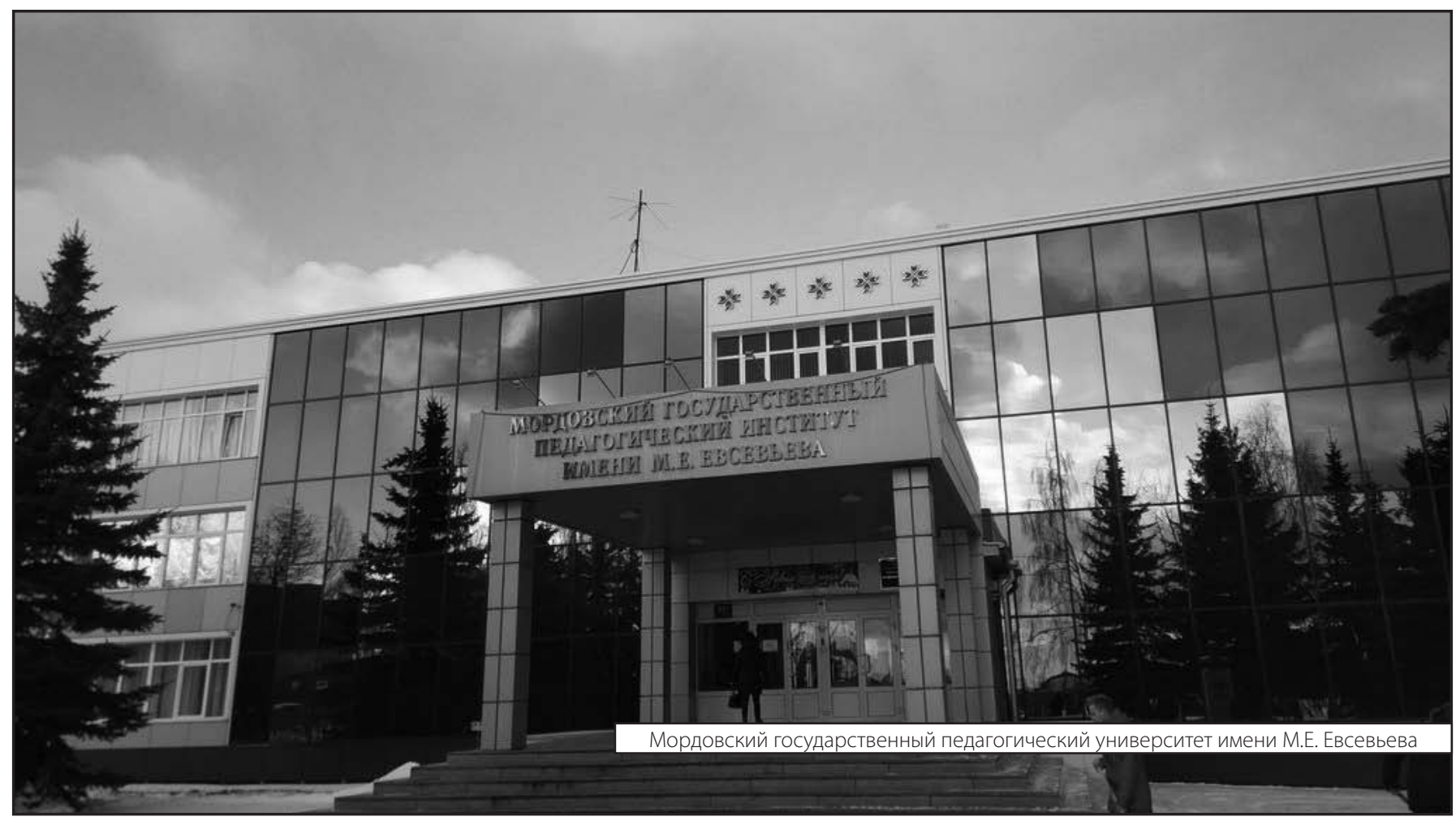

